\title{
Dominique Gaspard, Mercuriade, Tragédie (1605)
}

\section{Monica Pavesio}

\section{(2) OpenEdition}

\section{Journals}

\section{Edizione digitale}

URL: http://journals.openedition.org/studifrancesi/5917

DOI: 10.4000/studifrancesi.5917

ISSN: 2427-5856

\section{Editore}

Rosenberg \& Sellier

\section{Edizione cartacea}

Data di pubblicazione: 1 mai 2011

Paginazione: 161

ISSN: 0039-2944

\section{Notizia bibliografica digitale}

Monica Pavesio, «Dominique Gaspard, Mercuriade, Tragédie (1605)», Studi Francesi [Online], 163 (LV | I) |

2011, online dal 30 novembre 2015, consultato il 12 janvier 2021. URL: http://

journals.openedition.org/studifrancesi/5917 ; DOI: https://doi.org/10.4000/studifrancesi.5917

\section{Questo documento è stato generato automaticamente il 12 janvier 2021.}

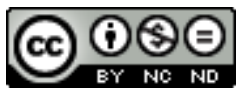

Studi Francesi è distribuita con Licenza Creative Commons Attribuzione - Non commerciale - Non opere derivate 4.0 Internazionale. 


\title{
Dominique Gaspard, Mercuriade, Tragédie (1605)
}

\author{
Monica Pavesio
}

\section{NOTIZIA}

DOMINIQUE GASPARD, Mercuriade, Tragédie (1605), Editée par Alain CULLIÈRE, Genève, Droz, 2009 , pp. 267.

1 Composta nel 1605 dal religioso loreno Dominique Gaspard, la tragedia Mercuriade porta in scena l'epopea ungherese di Filippo Emanuele di Lorena, secondo Duca di Mercœur, dal momento in cui raggiunse l'esercito imperiale in lotta contro i Turchi, nell'ottobre del 1599, fino alla sua morte sopraggiunta a Norimberga, sulla strada del ritorno, nel 1602 .

2 Si tratta dunque di una delle rare opere del tempo a portare in scena un soggetto contemporaneo, che ha lo scopo di perpetuare la memoria di un personaggio storico, che si appresta a entrare nella leggenda. D'altra parte Gaspard, come illustra il curatore nella ricca introduzione, appartenendo a un ordine, quello della Santa Trinità, che si occupava del riscatto dei cristiani prigionieri dei turchi, delle vittime delle Crociate e della pirateria barbaresca, era particolarmente sensibile alle lotte tra cristiani e musulmani alle porte dell'Europa, delle quali il duca di Mercœur fu uno dei principali protagonisti francesi.

3 La tragedia apologetica - che A. Cullière presenta in un'edizione critica accurata, con un ricco apparato di note sintattiche, storiche, geografiche, letterarie - riveste, inoltre, una certa importanza, perché è una delle pochissime testimonianze pervenuteci del teatro didattico dell'epoca, portato in scena nei collegi religiosi, non esclusivamente di ordine gesuitico.

4 Questo testo raro destinato alla rappresentazione scolastica, conservato in un manoscritto lacunoso del Musée Condé di Chantilly, si distingue dunque per l'originalità del soggetto e per l'interesse sul piano drammaturgico. 
5 Arricchiscono l'edizione critica una ricca bibliografia, un glossario esaustivo ed un indice dei nomi propri. 